\title{
Influence of the type of emphysema in the relationship between COPD and lung cancer
}

This article was published in the following Dove Press journal:

International Journal of COPD

Cecilia Mouronte-Roibás,' Alberto Fernández-Villar,' Alberto Ruano-Raviña, ${ }^{2}$ Cristina RamosHernández, ' Amara Tilve-Gómez, ${ }^{3}$ Paula Rodríguez-Fernández, ${ }^{3}$ Adriana Carolina Caldera Díaz, ${ }^{3}$ Míriam García VázquezNoguerol, ${ }^{3}$ Sara FernándezGarcía,' Virginia Leiro-Fernández'

'Pneumology Department, Álvaro Cunqueiro Hospital, Sanitary Area of Vigo, Neumovigol+i Investigation Group, Health Research Institute Galicia Sur (IIS Galicia Sur), SERGAS-UVIGO, Vigo, Spain; ${ }^{2}$ Public Health and Preventive Medicine Department, Medicine School, Santiago de Compostela University, CIBER of Epidemiology and Public Health, Madrid, Spain; ${ }^{3}$ Radiology Department, Hospital Sanitary Area of Vigo, Health Research Institute Galicia Sur (IIS Galicia Sur), SERGAS-UVIGO, Vigo, Spain

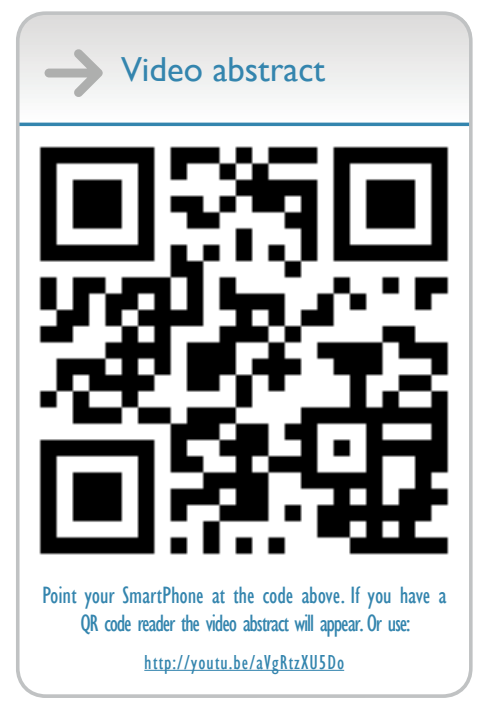

Correspondence: Alberto Fernández-Villar Pneumology Department, Álvaro Cunqueiro Hospital, Estrada Clara Campoamor, $n^{\circ} 341$, Beade, CP 36312, Vigo, Spain

Tel +349868I IIII

$\mathrm{Fax}+34986816029$

Email jose.alberto.fernandez.villar@sergas.es
Introduction: There are no studies analyzing the relationship between emphysema and lung cancer (LC). With this aim and in order to make some comparisons between different clinical variables, we carried out the present study.

Methods: This is a case-control study, patients with COPD and LC being the cases and subjects with stable COPD being the controls. Clinical and functional parameters, as well as the existence of radiological emphysema, were evaluated in a qualitative and quantitative way, using a radiological density of -950 Hounsfield units as a cutoff point in the images. The existence of several different types of emphysema (centrilobular, paraseptal, panacinar, or bullae) was analyzed, allowing patients to have more than one simultaneously. The extent to which lobes were involved was evaluated and the extension of emphysema was graduated for each type and location, following a quantitative scale. Differences between cases and controls were compared by using bivariate and multivariate analyzes with results expressed as OR and 95\% CI.

Results: We included 169 cases and 74 controls, 84\% men with a $\mathrm{FEV}_{1}$ (\%) of $61.7 \pm 18.5$, with $90.1 \%$ non-exacerbators. Most of them (50\%) were active smokers and $47.2 \%$ were ex-smokers. Emphysema was found in $80.2 \%$ of the subjects, the most frequent type being centrilobular (34.4\%). The only significantly different factor was the presence of paraseptal emphysema (alone or combined; $\mathrm{OR}=2.2[95 \% \mathrm{CI}=1.1-4.3, P=0.03]$ ), with adenocarcinoma being significantly more frequent in paraseptal emphysema with respect to other types $(67.2 \%$ vs $32.8 \%, P=0.03$ ).

Conclusion: Patients with COPD and paraseptal emphysema could be a risk group for the development of LC, especially adenocarcinoma subtype.

Keywords: COPD, emphysema, lung cancer, paraseptal

\section{Introduction}

Lung cancer (LC) is the leading cause of death between malignancies with a 5-year survival of around $15 \%$. COPD is the fourth cause of death in the world, with a prevalence of $10 \%{ }^{1,2}$ Tobacco consumption is the main risk factor for the development of COPD (followed by exposure to biomass smoke) and LC. ${ }^{1,2}$ Both the diseases share another series of genetic, epigenetic, environmental, inflammatory, and common oxidative stress characteristics. ${ }^{3,4}$ In fact, some studies suggest that COPD is a risk factor for the development of LC, regardless of smoking habits. ${ }^{5}$

Pulmonary emphysema is the dilation of air spaces distal to the terminal bronchioles accompanied by the destruction of their walls. ${ }^{6}$ Emphysema is a characteristic of some patients with COPD, although it may be present in different phenotypes and even in smokers without COPD criteria. ${ }^{2}$ Currently, computed tomography (CT) is the best method for the noninvasive detection of emphysema. ${ }^{7}$ So far, there are different conclusions in the available studies that explore the relationship between LC and 
emphysema, ${ }^{8-10}$ which can be explained by different methods of evaluating thoracic CT, ${ }^{11}$ observing that emphysema detected visually by an expert radiologist seems superior to an automatic detection when establishing it as a risk factor for developing LC, even independently of the presence of airflow obstruction. ${ }^{8,9}$ The existence of emphysema has traditionally been related to the squamous histological type. ${ }^{12}$

To our knowledge, there are no studies of phenotypic and multidimensional characterization of COPD with LC that can help us choose the most appropriate therapy and its prognosis. In addition, there are several types of emphysema, although there is no clear evidence about its relationship with the development of LC. ${ }^{13}$ For this reason and based on the potential association between COPD and LC, we developed this study, to better understand the interaction between both diseases and establish if there is any relationship between the type of pulmonary emphysema, its extension and the development of LC. To do this, we analyzed the profile of patients with COPD and LC (cases), comparing it with another group of patients with COPD without LC (controls).

\section{Methods}

\section{Study design and inclusion and exclusion criteria}

This is an observational case-control study in which patients with COPD from the Vigo University Hospital from January 2014 to September 2016 were included. Cases are patients with LC and COPD assessed in the Lung Cancer Rapid Diagnosis Unit (LCRDU), included in the study at the time of LC diagnosis, while controls were captured in a general pulmonary consultation that was carried out on the same days as the LCRDU, including patients with recently diagnosed COPD ( $<6$ months). Both the groups needed to have a CT at the time of inclusion in the study. Patients who did not want to participate, with contraindications or unable to perform spirometry correctly and those who did not want or did not need a chest CT scan were excluded. Afterwards, we performed univariate and multivariate analyses excluding those patients who did not have any kind of emphysema in the CT, as shown in the flowchart (Figure 1).

The LCRDU permits a diagnostic and staging process of LC and other thoracic neoplasms. Cases included in the study are from the LCRDU, where the diagnosis and staging of the LC are made according to a multidisciplinary approach and international guidelines. ${ }^{14}$ Emphysema was determined by experimented radiologists, who were not aware whether patients came from the case or control group, prior to their assessment of the CTs. The CT studies were performed in two devices: Lightspeed VCT of 64 rows of detectors (GE Medical Systems, Milwaukee, WI, USA) and Somatom Emotion of 16 rows of detectors (Siemens Medical Solutions, Enlargen, Germany).

The study was approved by the Ethics Committee for Clinical Research of Galicia (file 2013/439). All patients signed informed consent in writing, also for the anonymized publication of any CT images. Variables were included in an anonymized database to maintain the principles of confidentiality and data protection.

\section{Data collection}

Demographic data, occupational exposures, comorbidity by Charlson index, ${ }^{15}$ functional and radiological variables,

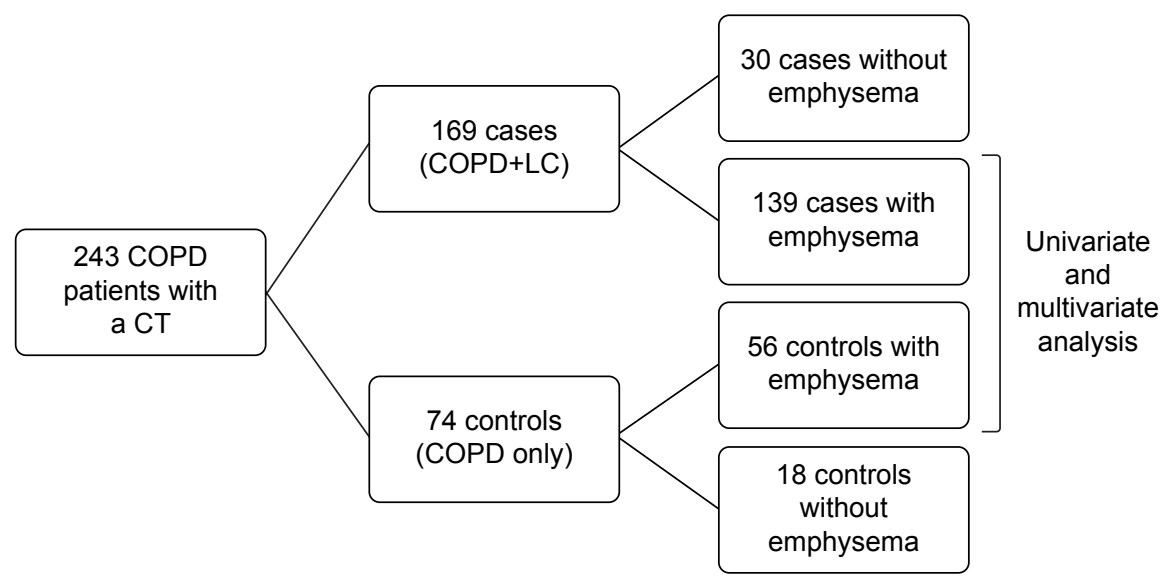

Figure I Flowchart of patients included in the study.

Abbreviations: CT, computed tomography; LC, lung cancer. 
and body mass index (BMI) were collected. Smokers were defined as those who had smoked $\geq 100$ cigarettes in their lifetime. Active smokers were those who had smoked more than one cigarette in the month before enrollment. The remaining smokers were classified as ex-smokers. Never smokers were patients who smoked $<100$ cigarettes during their lifetime. ${ }^{16}$ Spirometry was performed at the time of inclusion in this study, with a bronchodilator test and using the criteria of acceptability and reproducibility established in the guidelines of the Spanish Society of Respiratory Pathology ${ }^{17}$ using Quanjer Gli's reference values. ${ }^{18}$ The diffusion capacity was obtained using standard techniques in accordance with the recommendations of the American Thoracic Society. ${ }^{19}$

The diagnosis of LC was made after suggestive radiological findings with pathologic confirmation in all cases. The histological type was obtained by reviewing the pathology report. We also analyzed the stage at diagnosis according to the 8th TNM (Tumor size, Nodes and Metastasis). ${ }^{20}$ We used the Global initiative of Obstructive Lung Disease (GOLD) and Guía Española de la EPOC classifications, ${ }^{2,21}$ including the COPD assessment test (CAT) $)^{22}$ and the BODE or $\mathrm{BODEx}^{23,24}$ indexes.

We reviewed in how many cases alpha-1 antitrypsin (A1AT) was determined and analyzed its value.

Emphysema evaluation was initially performed qualitatively defined as the existence or not of any type of emphysema in the thoracic study, that is, $\geq 1 \%$, using a radiological density of -950 Hounsfield units (HU) as a cutoff point in the images. ${ }^{25}$ Emphysema was evaluated with a 64-slice volumetric scanner, and the $-950 \mathrm{HU}$ areas were determined automatically by the scanner software. A more restrictive cutoff point ( $\geq 25 \%$ ) was also used. In addition, the existence of different types of emphysema (centrilobular, paraseptal, panacinar, or bullae) was analyzed, and the patients could have more than one simultaneously, ${ }^{13,26-28}$ so several analyzes were performed combining different types of emphysema. Centrilobular emphysema was defined as a dilation of the airway on the respiratory bronchiole; paraseptal emphysema as changes in the more distal alveoli adjacent to the pleural surface or interlobular septa; panlobular as that distributed throughout the pulmonary lobe; and bullae were defined as localized areas of emphysema greater than a centimeter in diameter. ${ }^{13,26-28}$ Lobe involvement was also assessed, and emphysema severity was subjectively graded for each type and location, following a modified scale from the National Emphysema Treatment Trial (NETT) guidelines
(0: no emphysema, $1: 0 \%-25 \% ; 2: 25 \%-50 \% ; 3: 50 \%-75 \%$; 4: $75 \%-100 \%)$. $^{29,30}$

\section{Statistical analysis}

A descriptive analysis of all the variables was carried out, as well as bivariate analysis. We included variables with a significance $<0.10$ in the bivariate analysis in a logistic regression model to evaluate the existence of interaction between variables, excluding those who showed interaction with the type of emphysema, trying to minimize biases, as assessing the type of emphysema was the aim of this study. Afterwards, we performed a multivariate analysis (by the conditional forward method, including those variables with a significance $<0.10$ in the bivariate analysis and after minimizing any interactions between variables) to compare cases and controls, as well as cases and controls with emphysema. Student's $t$-test was used for the quantitative variables and the chi-squared test to compare the percentages in the qualitative ones. Our significance limit was $P<0.05$. The analysis was performed with the SPSS 21.0 program (IBM Corporation, Armonk, NY, USA).

\section{Results}

We included 243 patients, 169 cases and 74 controls, with a mean age of $67.9 \pm 9.9$ years, most of them being males (205 patients, $84.4 \%$ ).

About 121 patients (50\%) were active smokers, 115 (47.2\%) ex-smokers, three (1.2\%) never smokers, and another three (1.2\%) had environmental exposure to tobacco smoke. Most patients were non-exacerbators (90.1\%), with GOLD I-II in 169 cases (69.8\%). About 55.9\% of patients were in GOLD group A, 34.1\% in B, $2.4 \%$ in C, and $6.5 \%$ of patients in D. Mean $\mathrm{FEV}_{1}$ was $61.7 \pm 18.5$, with a CAT of 10.4 \pm 6.8 , a BODEx of $1.8 \pm 1.6$ and a Charlson index of $2.5 \pm 1.6$.

A1AT levels were available for $71.3 \%$ of patients. The mean value of A1AT was $156.5 \pm 45.3 \mathrm{mg} / \mathrm{dL}$. There were only three patients with A1AT deficiency, one case and two controls.

Out of the 169 patients with LC, 63 (40.4\%) were in stages I-IIIa and 93 (59.6\%) in stages IIIb-IV. The most frequent histological type was adenocarcinoma (41.2\%), followed by squamous $(34.5 \%)$, small cell $(16.4 \%)$, and undifferentiated $(7.9 \%)$.

A bivariate analysis was performed comparing case and control characteristics independently of the existence of emphysema. There was a higher percentage of males 
Table I Characteristics of cases (COPD + LC) and controls (COPD) with emphysema

\begin{tabular}{|c|c|c|c|}
\hline Variable & $\begin{array}{l}\text { Cases (LC + COPD) with } \\
\text { emphysema }(n=139)\end{array}$ & $\begin{array}{l}\text { Controls (COPD) with } \\
\text { emphysema }(n=56)\end{array}$ & $P$-value \\
\hline Sex, male (\%) & $122(87.8)$ & $44(78.6)$ & 0.07 \\
\hline Age, years $\pm S D$ & $68.5 \pm 9.3$ & $65.4 \pm 10.3$ & 0.05 \\
\hline Pack-years \pm SD & $55.9 \pm 26.9$ & $49.6 \pm 22.1$ & 0.11 \\
\hline Laboral exposure (\%) & $51(38.6)$ & $19(33.9)$ & 0.36 \\
\hline $\mathrm{FEV} \% \pm \mathrm{SD}$ & $62.7 \pm 18.8$ & $58.2 \pm 20.1$ & 0.19 \\
\hline $\mathrm{DLCO} \% \pm \mathrm{SD}$ & $57.4 \pm \mid 4.8$ & $58.9 \pm 18.4$ & 0.07 \\
\hline GOLD III-IV (\%) & $39(28.1)$ & $19(33.9)$ & 0.27 \\
\hline GOLD C-D (\%) & $15(10.8)$ & $7(12.5)$ & 0.46 \\
\hline Exacerbators (\%) & $13(9.4)$ & $7(12.5)$ & 0.34 \\
\hline Paraseptal emphysema (alone or combined) (\%) & $80(57.5)$ & $25(44.6)$ & 0.07 \\
\hline Centrolobulillar emphysema (alone or combined) (\%) & $101(72.6)$ & $38(67.8)$ & 0.31 \\
\hline$>2$ lobes with emphysema (\%) & I3I (94.2) & $54(96.4)$ & 0.41 \\
\hline SSLL with emphysema (\%) & $|3|(94.2)$ & $42(75)$ & $<0.001$ \\
\hline$>50 \%$ of emphysema (\%) & $34(24.5)$ & $18(32.1)$ & 0.23 \\
\hline $\mathrm{BMI}<25 \mathrm{~kg} / \mathrm{m}^{2}(\%)$ & $64(46.1)$ & $21(37.5)$ & 0.14 \\
\hline$C A T \pm D E$ & $10.4 \pm 6.6$ & $10.6 \pm 7.1$ & 0.84 \\
\hline BODEx $\pm \mathrm{DE}$ & $1.8 \pm 1.7$ & $2.1 \pm 1.6$ & 0.28 \\
\hline Charlson $\pm \mathrm{DE}$ & $2.6 \pm 1.7$ & $2.3 \pm 1.7$ & 0.27 \\
\hline
\end{tabular}

Note: Results are expressed as " $\mathrm{n}$ and (\%)" for qualitative variables and as "mean \pm SD" for quantitative variables.

Abbreviations: BMI, body mass index; CAT, COPD assessment test; DLCO, carbon dioxide diffusion capacity; FEVI, forced expiratory volume in the first second; GOLD, Global Initiative of chronic Obstructive Lung Disease; LC, lung cancer; SSLL, superior lobes.

in the group of cases $(87.6 \%$ vs $77 \%, P=0.03)$; they were older (69.2 \pm 9.6 vs $64.9 \pm 10.2$ years; $P=0.003)$, heavy smokers (pack-years $>60: 27.8 \%$ vs $13.5 \%, P=0.03$ ), and thinner (BMI $<25 \mathrm{~kg} / \mathrm{m}^{2}: 41.4 \%$ vs $29.7 \% ; P=0.04$ ). There were no differences in terms of occupational exposure, pulmonary function at diagnosis, severity of COPD, exacerbations, or comorbidity. We found no differences in relation to the existence or not of emphysema, using two cutoff points ( $\geq 1 \%$ and $\geq 25 \%$ ). The results of the bivariate analysis comparing the characteristics of cases and controls

Table 2 Comorbidities of cases (COPD + LC) and controls (COPD) with emphysema

\begin{tabular}{|l|l|l|}
\hline Variable & $\begin{array}{l}\text { Cases (LC + COPD) with } \\
\text { emphysema (n=139) }\end{array}$ & $\begin{array}{l}\text { Controls (COPD) with } \\
\text { emphysema (n=56) }\end{array}$ \\
\hline Previous lung disease, $\mathrm{n}(\%)$ & $55(39.6)$ & $5(8.9)$ \\
\hline Previous COPD, $\mathrm{n}(\%)$ & $50(36)$ & $5(8.9)$ \\
\hline Heart disease, $\mathrm{n}(\%)$ & $80(57)$ & $24(42.8)$ \\
\hline Ischemic, $\mathrm{n}(\%)$ & $44(31.6)$ & $15(26.8)$ \\
\hline Arrhythmia, $\mathrm{n}(\%)$ & $24(17.4)$ & $5(8.9)$ \\
\hline Congestive heart failure, $\mathrm{n}(\%)$ & $12(8.6)$ & $4(7.1)$ \\
\hline Peripheric vascular disease, $\mathrm{n}(\%)$ & $40(28.8)$ & $8(14.3)$ \\
\hline Cerebrovascular disease, $\mathrm{n}(\%)$ & $5(3.6)$ & $\mathrm{I}(\mathrm{I} .8)$ \\
\hline Dementia, $\mathrm{n}(\%)$ & $9(6.5)$ & $3(5.3)$ \\
\hline Peptic ulcer, $\mathrm{n}(\%)$ & $10(7.2)$ & $0(0)$ \\
\hline Liver disease, $\mathrm{n}(\%)$ & $6(4.3)$ & $3(5.3)$ \\
\hline Diabetes mellitus, $\mathrm{n}(\%)$ & $49(35.2)$ & $12(21.4)$ \\
\hline Renal disease, $\mathrm{n}(\%)$ & $2(1.4)$ & $4(7.1)$ \\
\hline Previous neoplasm, $\mathrm{n}(\%)$ & $20(14.4)$ & $16(28.6)$ \\
\hline
\end{tabular}

Abbreviation: LC, lung cancer. 


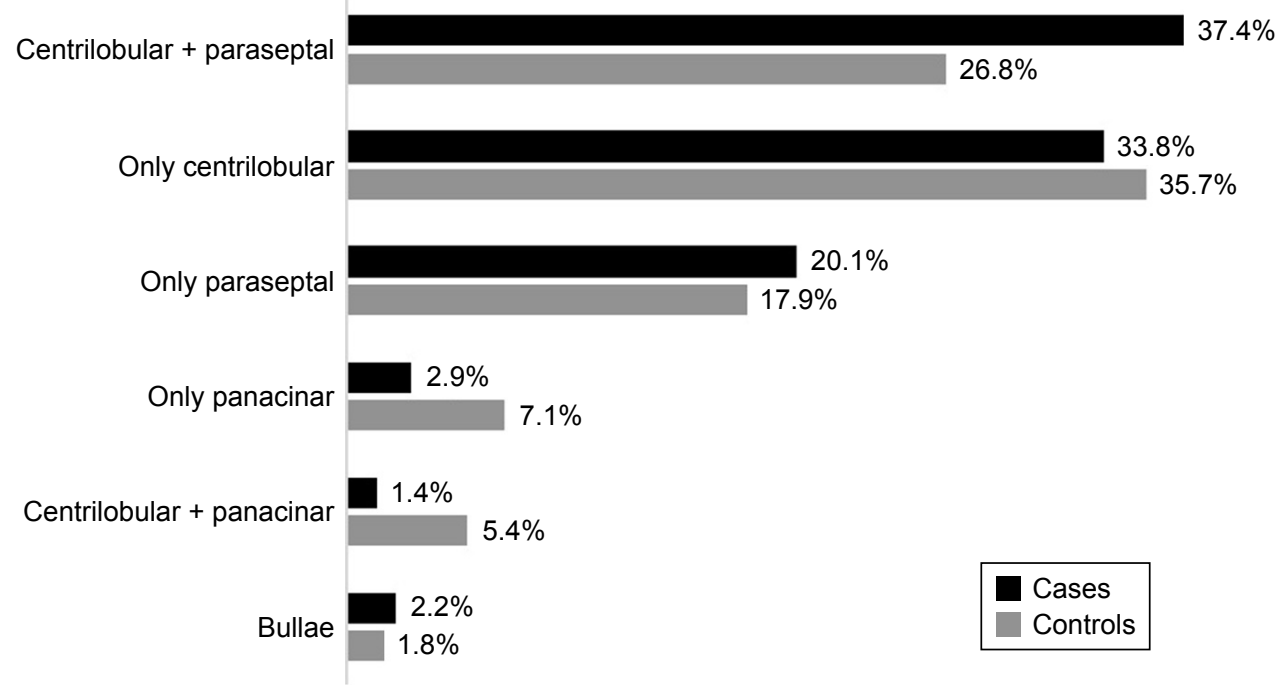

Figure 2 Emphysema distribution between cases and controls.

with emphysema are shown in Table 1, and comorbidities are listed in Table 2. To avoid that the criterion to define emphysema as $\geq 1 \%$ could be excessively lax, we repeated the analysis defining emphysema as a cutoff point $\geq 25 \%$, again without significant differences between cases and controls $(54.4 \%$ vs $446 \%, P=0.10)$. After adjusting with the rest of the variables using a logistic regression model, no significant differences were found between the two groups.

Overall, the most frequent type of emphysema was centrilobular (43.2\%), affecting more than two lobes in $77 \%$ of cases, and in the visual scale, it was considered extensive in $29.1 \%$. The involvement was predominantly in the upper lobes in $97.4 \%$ of the patients. Of the total of 243 patients, 195 (80.2\%) had emphysema: 139 cases (82.2\%) and 56 controls (75.7\%) (Figure 2). The group of 139 cases had emphysema located in the upper lobes (94.2\%), and the cancer was in the lobe with more emphysema within each patient in $58.6 \%$ of cases.

All variables with $P<0.10$ in the bivariate analysis were included in a multivariate model, in which patients with LC and COPD with emphysema were characterized by presenting a higher prevalence of paraseptal emphysema $(\mathrm{OR}=2.17$ [95\% CI 1.095-4.301; $P=0.026]$ ) (Table 3). As part of a secondary analysis, we analyzed the characteristics of patients with paraseptal emphysema, with respect to those patients who did not present it for the entire cohort of cases and controls. We did not find differences in terms of sex, age, smoking, stage of LC at diagnosis, severity or symptomatic repercussion of COPD, lung function, or comorbidity. Nevertheless, adenocarcinoma was significantly more fre- quent in paraseptal emphysema compared to other types of emphysema ( $67.2 \%$ vs $32.8 \%, P=0.03)$. None of our patients with LC had pulmonary fibrosis.

\section{Discussion}

Our study is the first that shows an association between a specific type of emphysema (paraseptal) and the presence of LC in patients with COPD. This finding provides new information about the characterization of patients with COPD and LC, given that, although there seems to be a relationship between the existence of emphysema and the risk of developing LC, to our knowledge no study has focused specifically on the influence of the different types of emphysema in the risk of LC.

Evidence about the association between emphysema and LC came from studies that included a semiquantitative assessment of emphysema by experienced radiologists, ${ }^{6,8,9}$ even showing a risk for patients with emphysema but without airflow obstruction. However, it seems that the relationship

Table 3 Multivariant analysis relating cases (COPD + LC) and controls (COPD) with emphysema

\begin{tabular}{|l|l|l|}
\hline Variable & OR $(95 \%$ CI) & P-value \\
\hline Sex $($ male) & I.63 $(0.58-4.54)$ & 0.35 \\
\hline Age & I.03 $(0.99-1.07)$ & 0.16 \\
\hline BMI $<25 \mathrm{~kg} / \mathrm{m}^{2}$ & $0.56(0.27-1.24)$ & 0.58 \\
\hline Pack-years & I.0I (0.99-I.02) & 0.25 \\
\hline $\begin{array}{l}\text { Paraseptal emphysema } \\
\text { (alone or combined) }\end{array}$ & $2.17(\mathrm{I} .09-4.30)$ & 0.03 \\
\hline
\end{tabular}

Abbreviation: BMI, body mass index. 
is not as consistent when the evaluation of the existence of emphysema is carried out with a quantitative system. ${ }^{10}$ We found no association between the existence of emphysema and the presence of $\mathrm{LC}$, despite having undergone a semiquantitative type assessment by four experienced radiologists. In our case, each study was evaluated by only one of the radiologists, defining emphysema from a cutoff point of $\geq 1 \%$, which could be a possible bias of the study, as the inter and intraoperator concordance using a visual scale is low. ${ }^{31}$ However, to minimize this effect, we repeated the analyses, using a cutoff point on the visual scale of $\geq 25 \%$, again without any significant relationship. Given that available studies about the relationship between emphysema and LC show no data about the types of emphysema, it is possible that the distribution between forms of emphysema within each study is heterogeneous, therefore contributing to the disparity of results.

Although we found that centrilobular was the most frequent type of emphysema (similar to other published data), ${ }^{13,32}$ paraseptal emphysema was the one that showed a relationship with LC in patients with COPD (Figure 2). Centrilobular emphysema is usually associated with higher age, more smoking and severity, ${ }^{13,32}$ while paraseptal predominantly affects upper lobes, ${ }^{33,34}$ is associated with male sex, older age, and diffuse interstitial lung disease, being the one that occurs most frequently in cases with the combination of emphysema and fibrosis, ${ }^{13,34}$ although in our case, no patient had pulmonary fibrosis. Paraseptal emphysema is not clinically relevant until advanced stages ${ }^{33}$ and has not been shown to be related to the development of symptoms in COPD, to the degree of obstruction, or to smoking history. ${ }^{13,32}$ The visual evaluation of the CT is the best method for the noninvasive detection of all types of emphysema, since its results usually coincide with those obtained in histological sampling. ${ }^{13}$ The exact mechanism of lung parenchymal damage involved in the relationship between emphysema and the development of LC is not clearly understood and, in fact, the present study is the first suggesting any relationship between paraseptal emphysema and the development of LC in COPD patients. ${ }^{34}$ Multiple pulmonary matrix metalloproteinases (MMPs) are directly associated with emphysema subtypes identified by CT imaging. ${ }^{35}$ This suggests that MMPs may play a significant role in tissue destruction and thus lead to carcinogenesis. The presence of paraseptal emphysema in our sample could be related to the high prevalence of adenocarcinoma that we have observed in this type of emphysema, as it is a peripheral tumor with later clinical manifestations. ${ }^{36}$
In our study, patients with LC had emphysema located predominantly in the upper lobes, obtaining results similar to those in the literature. ${ }^{37}$ Hohberger et $\mathrm{al}^{29}$ found that, when comparing the location of a malignant nodule with other pulmonary regions of the same patient, the probability of having a more severe emphysema in the area where LC was present was significantly higher. In our series, we did not find that the tumor was in the lobe with more emphysema within each patient.

Adenocarcinoma was the most prevalent histological type of LC, with results similar to those of other series. ${ }^{38,39}$ This could be due to several factors such as changes in the characteristics of cigarettes, changes in the classification of adenocarcinomas, the incorporation of women into smoking, and the greater number of diagnoses in asymptomatic patients, given that adenocarcinoma is a more peripheral tumor that takes longer to cause symptoms. ${ }^{36}$

Most of our patients are non-exacerbators, GOLD I-II, and A-B. We believe that this is a benefit for several reasons. The first is that this is the group of patients with COPD that is most interesting to characterize, because due to their functional situation, they are the ones who can benefit the most from aggressive therapeutic strategies when it comes to addressing their oncological pathology. On the other hand, there is evidence to suggest that the risk of developing LC and dying from it is greater in patients with GOLD I-II, while patients with GOLD III-IV die more from COPD itself. ${ }^{40}$

Patients with COPD and LC were older and with a lower BMI than controls (patients with COPD without LC). The greater age could be due to the latency time necessary for COPD to lead to the development of LC, whereas the lower BMI could be due to the fact that they are mostly non-exacerbators with emphysema. We did not find differences between cases and controls in terms of phenotyping, pulmonary function, CAT, BODEx, or comorbidity measured by Charlson Index. Nevertheless, cases with emphysema tended to have a greater number of COPD diagnoses prior to inclusion in the study, more peripheral vascular pathology, and a higher prevalence of gastric ulcer, diabetes mellitus, and previous neoplasms (Table 2).

Our study presents limitations due to its case and control design. The number of controls is less than the number of cases. Controls had to be patients with recently diagnosed COPD ( $<6$ months) that also required the performance of a chest CT. Recruitment was made from our outpatient clinics, in which the percentage of recently diagnosed COPD represents a low proportion of our activity, these patients being usually managed by primary care. In addition, all 
controls needed a CT to be included in the study and not all patients with COPD require the performance of a CT. ${ }^{2} \mathrm{On}$ the other hand, the existence, the distribution by lobes, and the quantification of emphysema have been evaluated by expert radiologists, which implies certain subjectivity; although there seems to be good intra and interobserver correlation when evaluating the type of emphysema (kappa 0.70). ${ }^{41}$ Although we have used a visual scale to establish the severity of emphysema, we have tried to compensate for interobserver variability by using two different cutoff points ( $\geq 1 \%$ and $\geq 25 \%$ ) for the diagnosis of emphysema, without this implying changes in the results. In addition, although radiologists were unaware of the diagnosis of malignancy, their evaluation of the studies may have been biased by the existence of lesions suggestive of malignancy in cases with LC. However, patients with benign nodular lesions, which were included in the control group, were not excluded from the study. Also, our results show an association with LC whether emphysema is purely paraseptal or associated with the most frequent type of emphysema, the centrilobular. This could be a limitation, although the reality in our clinical practice is that patients with emphysema present a combination of different types of emphysema simultaneously and, therefore, present conditions like those of the patients in our study. On the other hand, we did not analyze radon exposure or family history, although we do analyze occupational exposure to agents such as asbestos, arsenic, diesel emissions, and some forms of silicon and chromium. Also, a limitation of our study is that A1AT levels were not available for all patients. However, they were available in $71.3 \%$ of the whole.

Our study has certain advantages. This is the first work that analyses the relationship between the type of emphysema in patients with COPD and the development of LC, and the sample size is reasonably large. In addition, we carried out a detailed epidemiological, clinical, and functional evaluation, minimizing the loss of LC patients by recruiting them through a consultation that sees $>95 \%$ of LC in our area, also carrying out a very complete characterization of COPD following the two most important guidelines used in our country. ${ }^{2,15}$

\section{Conclusion}

The present study shows that paraseptal emphysema in patients with COPD is more frequent in those cases who also have LC. Therefore, patients with COPD and paraseptal emphysema could be a risk group for the development of LC, especially adenocarcinoma. The results of this study justify exploring the benefit of interventions to prevent or detect LC in patients with COPD in which the presence of paraseptal emphysema has been observed and supports the benefit of performing thoracic CT in COPD patients in whom emphysema is suspected.

\section{Acknowledgments}

This study receives funding from the project 110/2016 of the Spanish Society of Respiratory Pathology (SEPAR). This study is part of the work aimed at the completion of the $\mathrm{PhD}$ Degree of Cecilia Mouronte-Roibás.

\section{Disclosure}

The authors report no conflicts of interest in this work.

\section{References}

1. Ferlay J, Soerjomataram I, Dikshit R, et al. Cancer incidence and mortality worldwide: sources, methods and major patterns in GLOBOCAN 2012. Int J Cancer. 2015;136(5):E359-E386.

2. Miravitlles M, Soler-Cataluña JJ, Calle M, et al. Spanish Guidelines for Management of Chronic Obstructive Pulmonary Disease (GesEPOC) 2017. Pharmacological Treatment of Stable Phase. Arch Bronconeumol. 2017;53(6):324-335.

3. Seijo LM, Zulueta JJ. Understanding the links between lung cancer, COPD, and emphysema: a key to more effective treatment and screening. Oncology. 2017;31(2):93-102.

4. Sandelin M, Mindus S, Thuresson M, et al. Factors associated with lung cancer in COPD patients. Int J Chron Obstruct Pulmon Dis. 2018; 13:1833-1839.

5. Young RP, Hopkins RJ, Christmas T, Black PN, Metcalf P, Gamble GD. COPD prevalence is increased in lung cancer, independent of age, sex and smoking history. Eur Respir J. 2009;34(2):380-386.

6. American Thoracic Society. Standards for diagnosis and care of patients with chronic obstructive pulmonary disease. Am J Respir Crit Care Med. 1995;152(5):557-5120.

7. Madani A, Keyzer C, Gevenois PA. Quantitative computed tomography assessment of lung structure and function in pulmonary emphysema. Eur Respir J. 2001;18(4):720-730.

8. de Torres JP, Bastarrika G, Wisnivesky JP, et al. Assessing the relationship between lung cancer risk and emphysema detected on low-dose CT of the chest. Chest. 2007;132(6):1932-1938.

9. Wilson DO, Weissfeld JL, Balkan A, et al. Association of radiographic emphysema and airflow obstruction with lung cancer. Am J Respir Crit Care Med. 2008;178(7):738-744.

10. Maldonado F, Bartholmai BJ, Swensen SJ, Midthun DE, Decker PA, Jett JR. Are airflow obstruction and radiographic evidence of emphysema risk factors for lung cancer? A nested case-control study using quantitative emphysema analysis. Chest. 2010;138(6):1295-1302.

11. Turner MC, Chen Y, Krewski D, Calle EE, Thun MJ. Chronic obstructive pulmonary disease is associated with lung cancer mortality in a prospective study of never smokers. Am J Respir Crit Care Med. 2007; 176(3):285-290.

12. Smith BM, Schwartzman K, Kovacina B, et al. Lung cancer histologies associated with emphysema on computed tomography. Lung Cancer. 2012;76(1):61-66.

13. Smith BM, Austin JHM, Newell JD, et al. Pulmonary emphysema subtypes on computed tomography: the MESA COPD study. Am J Med. 2014;127(1):94.e7-23.

14. Leiro-Fernández V, Botana-Rial M, Tilve-Gómez A, RepresasRepresas C, Pallarés-Sanmartín A, Fernández-Villar A. Effectiveness of a protocolized system to alert pulmonologists of lung cancer radiological suspicion. Clin Transl Oncol. 2014;16(1):64-68. 
15. Charlson ME, Pompei P, Ales KL, Mackenzie CR. A new method of classifying prognostic comorbidity in longitudinal studies: development and validation. J Chronic Dis. 1987;40(5):373-383.

16. Henschke CI, Yip R, I-ELCAP Investigators, et al. CT screening for lung cancer: Importance of emphysema for never smokers and smokers. Lung Cancer. 2015;88(1):42-47.

17. García-Río F, Calle M, Spanish Society of Pulmonology and Thoracic Surgery (SEPAR), et al. Spirometry. Spanish Society of Pulmonology and Thoracic Surgery (SEPAR). Arch Bronconeumol. 2013;49(9): 388-401.

18. Quanjer PH, Stanojevic S, ERS Global Lung Function Initiative, et al. Multi-ethnic reference values for spirometry for the 3-95-yr age range: the global lung function 2012 equations. Eur Respir J. 2012;40(6): 1324-1343.

19. American Thoracic Society. American Thoracic Society. Single-breath carbon monoxide diffusing capacity (transfer factor). Recommendations for a standard technique - 1995 update. Am J Respir Crit Care Med. 1995;152(6 Pt 1):2185-2198.

20. Detterbeck FC, Boffa DJ, Kim AW, Tanoue LT. The Eighth Edition Lung Cancer Stage Classification. Chest. 2017;151(1):193-203.

21. Vogelmeier CF, Criner GJ, Martinez FJ, et al. Global Strategy for the Diagnosis, Management, and Prevention of Chronic Obstructive Lung Disease 2017 Report. GOLD Executive Summary. Am J Respir Crit Care Med. 2017;195(5):557-582.

22. Jones PW, Harding G, Berry P, Wiklund I, Chen WH, Kline Leidy N. Development and first validation of the COPD Assessment Test. Eur Respir J. 2009;34(3):648-654.

23. Celli BR, Cote CG, Marin JM, et al. The body-mass index, airflow obstruction, dyspnea, and exercise capacity index in chronic obstructive pulmonary disease. $N$ Engl J Med. 2004;350(10):1005-1012.

24. Soler-Cataluña JJ, Martínez-García MA, Sánchez LS, Tordera MP, Sánchez PR. Severe exacerbations and BODE index: two independent risk factors for death in male COPD patients. Respir Med. 2009;103(5): 692-699.

25. Müller NL, Staples CA, Miller RR, Abboud RT. "Density mask". An objective method to quantitate emphysema using computed tomography. Chest. 1988;94(4):782-787.

26. Leopold JG, Gough J. The centrilobular form of hypertrophic emphysema and its relation to chronic bronchitis. Thorax. 1957;12(3):219-235.

27. Pratt PC, Kilburn KH. A modern concept of the emphysemas based on correlations of structure and function. Hum Pathol. 1970;1(3): $443-463$.
28. Hansell DM, Bankier AA, Macmahon H, Mcloud TC, Müller NL, Remy J. Fleischner Society: glossary of terms for thoracic imaging. Radiology. 2008;246(3):697-722.

29. Hohberger LA, Schroeder DR, Bartholmai BJ, et al. Correlation of regional emphysema and lung cancer: a lung tissue research consortiumbased study. J Thorac Oncol. 2014;9(5):639-645.

30. Fishman A, Martinez F, National Emphysema Treatment Trial Research Group, et al; A randomized trial comparing lung-volume-reduction surgery with medical therapy for severe emphysema. $N$ Engl J Med. 2003;348(21):2059-2073.

31. Mascalchi M, Diciotti S, Sverzellati N, et al. Low agreement of visual rating for detailed quantification of pulmonary emphysema in wholelung CT. Acta Radiol. 2012;53(1):53-60.

32. Satoh K, Kobayashi T, Misao T, et al. CT assessment of subtypes of pulmonary emphysema in smokers. Chest. 2001;120(3):725-729.

33. Edge J, Simon G, Reid L. Peri-acinar (paraseptal) emphysema: its clinical, radiological, and physiological features. Br J Dis Chest. 1966; 60(1):10-18.

34. Araki T, Nishino M, Zazueta OE, et al. Paraseptal emphysema: Prevalence and distribution on CT and association with interstitial lung abnormalities. Eur J Radiol. 2015;84(7):1413-1418.

35. Ostridge K, Williams N, Kim V, et al. Distinct emphysema subtypes defined by quantitative CT analysis are associated with specific pulmonary matrix metalloproteinases. Respir Res. 2016;17(1):92.

36. Brambilla E, Travis WD. Lung cancer. In: Stewart BW, Wild CP (editors). World Cancer Report. Lyon: World Health Organization; 2014

37. Bae K, Jeon KN, Lee SJ, et al. Severity of pulmonary emphysema and lung cancer: analysis using quantitative lobar emphysema scoring. Medicine. 2016;95(48):e5494.

38. Leiro-Fernández V, Mouronte-Roibás C, Ramos-Hernández C, et al. Changes in clinical presentation and staging of lung cancer over two decades. Arch Bronconeumol. 2014;50(10):417-421.

39. Janssen-Heijnen ML, Coebergh JW. The changing epidemiology of lung cancer in Europe. Lung Cancer. 2003;41(3):245-258.

40. Álvarez FV, Trueba IM, Sanchis JB, et al. Recommendations of the Spanish Society of Pneumology and Thoracic Surgery on the diagnosis and treatment of non-small-cell lung cancer. Arch Bronconeumol. 2016; 52 Suppl 1:2-62.

41. Smith BM, Pinto L, Ezer N, Sverzellati N, Muro S, Schwartzman K. Emphysema detected on computed tomography and risk of lung cancer: a systematic review and meta-analysis. Lung Cancer. 2012; 77(1):58-63.
International Journal of COPD

\section{Publish your work in this journal}

The International Journal of COPD is an international, peer-reviewed journal of therapeutics and pharmacology focusing on concise rapid reporting of clinical studies and reviews in COPD. Special focus is given to the pathophysiological processes underlying the disease, intervention programs, patient focused education, and self management protocols.

\section{Dovepress}

This journal is indexed on PubMed Central, MedLine and CAS. The manuscript management system is completely online and includes a very quick and fair peer-review system, which is all easy to use. Visit http://www.dovepress.com/testimonials.php to read real quotes from published authors. 